\title{
EFFECT OF NANOPOWDER ADDITION ON THE FLEXURAL STRENGTH OF ALUMINA CERAMIC: A WEIBULL MODEL ANALYSIS
}

\author{
DAIDONG GUO*, **, ${ }^{\#}$ SHIQUAN LIU* \\ *School of Materials Science and Engineering, University of Jinan, Jinan 250022, Shandong, China \\ **State Key Laboratory of Crystal Materials, Shandong University, Jinan 250100, Shandong, China \\ "E-mail: liusq_ujn@hotmail.com,mse_liusq@ujn.edu.cn
}

Submitted October 15, 2015; accepted March 1, 2016

\begin{abstract}
Keywords: Weibull distribution model, $\mathrm{Al}_{2} \mathrm{O}_{3}$ Ceramic, Nanopowder, Flexural Strength
Alumina ceramics were prepared either with micrometer-sized alumina powder (MAP) or with the addition of nanometersized alumina powder (NAP). The density, crystalline phase, flexural strength and the fracture surface of the two ceramics were measured and compared. Emphasis has been put on the influence of nanopowder addition on the flexural strength of $\mathrm{Al}_{2} \mathrm{O}_{3}$ ceramic. The analysis based on the Weibull distribution model suggests the distribution of the flexural strength of the NAP ceramic is more concentrated than that of the MAP ceramic. Therefore, the NAP ceramics will be more stable and reliable in real applications.
\end{abstract}

\section{INTRODUCTION}

Alumina ceramic materials have been intensively studied and widely used. They have many excellent performance, such as good mechanical strength (flexural strength of normally sintered products up to $250 \mathrm{MPa}$ ), high resistivity (room temperature resistivity of $10^{15} \Omega \cdot \mathrm{cm}$ ), good electrical insulation properties (dielectric strength of $15 \mathrm{kV} \cdot \mathrm{mm}^{-1}$ ), high hardness (Moh's hardness of 9), high melting point $\left(2050^{\circ} \mathrm{C}\right)$, anti-wear performance, excellent chemical stability, corrosion resistance to molten metal. Alumina ceramic is of great commercial importance. Its raw material is easily available with a low cost. However, like other ceramic materials, alumina ceramic also suffers from high brittleness, due to it is a covalent bonds dominated material [1].

The fracture of a material depends on its elastic modulus, fracture surface energy and the most dangerous crack [2]. With the same composition and preparing conditions, $\mathrm{Al}_{2} \mathrm{O}_{3}$ ceramics from the same batch have same intrinsic elastic modulus and fracture surface energy. Meanwhile, these $\mathrm{Al}_{2} \mathrm{O}_{3}$ ceramics also have different defects, such as crack, pore. The most dangerous crack in different samples $\mathrm{Al}_{2} \mathrm{O}_{3}$ is miscellaneous regarding the dimension and morphology. Therefore, in real applications, it is a great challenge to specify the loading capacity and the failure probability of an $\mathrm{Al}_{2} \mathrm{O}_{3}$ ceramic.

For a few ceramic specimens, the mean value of and the standard deviation of the fracture strength measurement data can be representative of the mechanical property of the ceramic. However, it does not work when a large amount of specimens are considered because of the noted dispersion of the measurement data [3]. In the latter case, Weibull model can be applied [4].

Weibull distribution function ${ }^{4}$ was built based on the weakest link concept in a material. Under an applied stress, the probability of material failure depends on the probability of unstable extending of a crack in a small local area. The function can be expressed as:

$$
P_{\mathrm{f}}=1-\exp \left[-\int_{V}\left(\frac{\sigma-\sigma_{0}}{\sigma_{\mathrm{u}}}\right)^{m} \mathrm{~d} V\right]
$$

where $P_{f}$ is the probability of material failure with the internal stress $\sigma ; V$ the volume of the sample; $\sigma_{\mathrm{u}}, \sigma_{0}$ and $m$ are the three important parameters of Weibull distribution function, that is, Location, Scale and Shape parameters, respectively. Usually $m$ is also referred to as Weibull modulus. When $m$ is larger than 1 , the greater the value of $m$, the more concentrated the distribution of the fracture strength [5].

The Weibull analysis of the fracture strength of a ceramic material follows the following steps.

1) If there are $N$ pieces of $\mathrm{Al}_{2} \mathrm{O}_{3}$ ceramic specimens, the fracture strength of these specimens will be ordered from the smallest one to the largest one as $\sigma_{1}<\sigma_{2}<$ $<\ldots<\sigma_{\mathrm{i}}<\ldots<\sigma_{\mathrm{N}}$

2) The calculation of Medium Rank $P_{\mathrm{i}}$, which is the fracture probability of ceramic specimens under the stress $\sigma_{\mathrm{i}}[6]$ :

$$
P_{\mathrm{i}}=\frac{i-0.302138}{N+0.396048}
$$

then, $N$ pieces of $\left(P_{\mathrm{i}}, \sigma_{\mathrm{i}}\right)$ pairs will be obtained. 
3) Set $P_{\mathrm{i}}$ and $\sigma_{\mathrm{i}}$ respectively as:

$$
\ln \ln \left(\frac{1}{1-P_{\mathrm{i}}}\right)=y
$$

$$
\ln \sigma_{i}=x
$$

A linear equation will be got from linear regression processing of those pairs $\left(P_{\mathrm{i}}, \sigma_{\mathrm{i}}\right)$ by the Least Square Method.

$$
y=A x+B
$$

The slope factor is $A$, and the intercept is $B$.

4) An approximate process of Equation 1 gives a linear relationship as:

$$
\ln \ln \left(\frac{1}{1-P_{\mathrm{f}}}\right)=m \ln \sigma-m \ln M O R_{0}
$$

Therefore, the shape parameter $m$ in Equations 1 and 6 correspond to the slope factor $A$ in Equation 5; - $m \ln M O R_{0}$ corresponds to the intercept $B$ in Equation 5. $M O R_{0}$ is the characteristic rupture modulus of the ceramic. Its value equals to the fracture strength at fracture probability of $63.212 \%$.

The Weibull distribution model is considered as the most effective route to do the failure analysis of brittle materials.

Nanopowders are characteristic of large surface areas, high ratios of grain boundary, short diffusion distance and the resultant high reactivity. It has been proved that introducing an appropriate amount of nanoparticles into normal powders benefits the sintering and densification process and improves the mechanical properties of the prepared ceramics [7-15].

In this work, the flexural strength of $\mathrm{Al}_{2} \mathrm{O}_{3}$ ceramic prepared with micrometer-sized alumina powder (MAP) and with adding nanometer-sized alumina powder (NAP) have been tested. The influence of the added nanoparticles on the flexural strength of the $\mathrm{Al}_{2} \mathrm{O}_{3}$ ceramics was analyzed based on the Weibull distribution model.

\section{EXPERIMENTAL SECTION}

Micro- and Nano-meter sized $\mathrm{Al}_{2} \mathrm{O}_{3}$ powders were from China Great Wall Aluminum Corporation and Aladdin Reagent (China) Co., LTD, respectively. Both powders had a purity of $99.9 \%$. Anhydrous ethanol was purchased from Tianjin Fuyu Special Chemicals co., LTD.; Polyvinyl alcohol (PVA) was purchased from Tianjin University, Tianjin Chemical Experiment Plant. Two types of $\mathrm{Al}_{2} \mathrm{O}_{3}$ ceramics were prepared. One started from the micrometer sized alumina powder; the other contained 5 wt. \% nano-meter sized $\mathrm{Al}_{2} \mathrm{O}_{3}$ powder besides the micrometer sized alumina. The samples are designated as MAP ceramic and NAP ceramic, respectively. Briefly, alumina powders and PVA were weighed and dispersed in anhydrous ethanol in an ultrasonic bath, followed by a thoroughly mixing in a planetary ball mill. After drying, the mixed powders were formed to green bodies in a steel mould under a uniaxial pressure of $100 \mathrm{MPa}$ for $1 \mathrm{~min}$. The MAP and NAP green bodies were sintered at $1650^{\circ} \mathrm{C}$ and $1600^{\circ} \mathrm{C}$ respectively for $12 \mathrm{~h}$.

The sintered $\mathrm{Al}_{2} \mathrm{O}_{3}$ ceramics were cut into specimens sized $40 \times 4 \times 3 \mathrm{~mm}$ and carefully ground and polished. Three point bending method was used to measure the flexural strength of the $\mathrm{Al}_{2} \mathrm{O}_{3}$ ceramics (CMT5504, MTS Industrial Systems (China) co., LTD.). The speed of loading was $0.5 \mathrm{~mm} \cdot \mathrm{min}^{-1} .30$ pieces of specimens were measured for both the MAP ceramics and NAP ceramics.

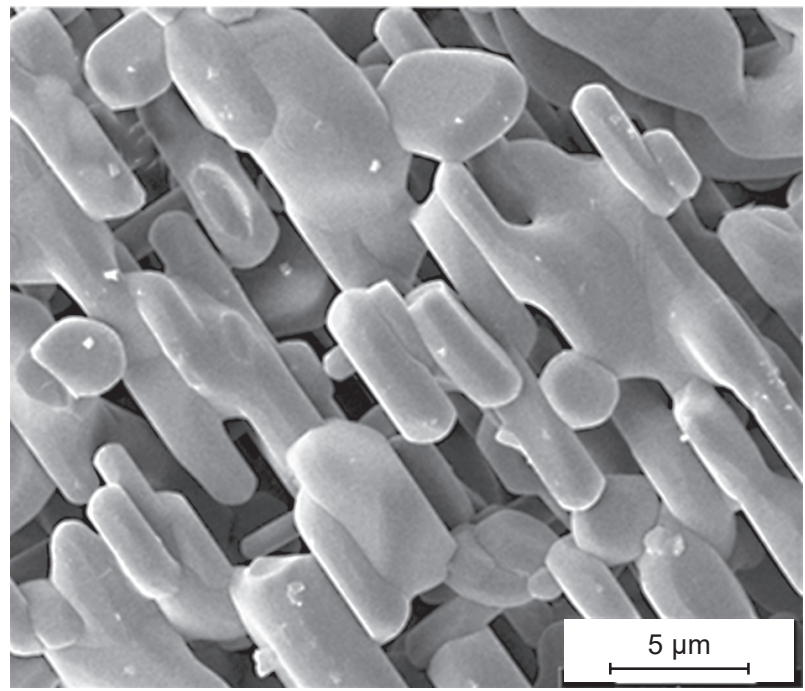

a)

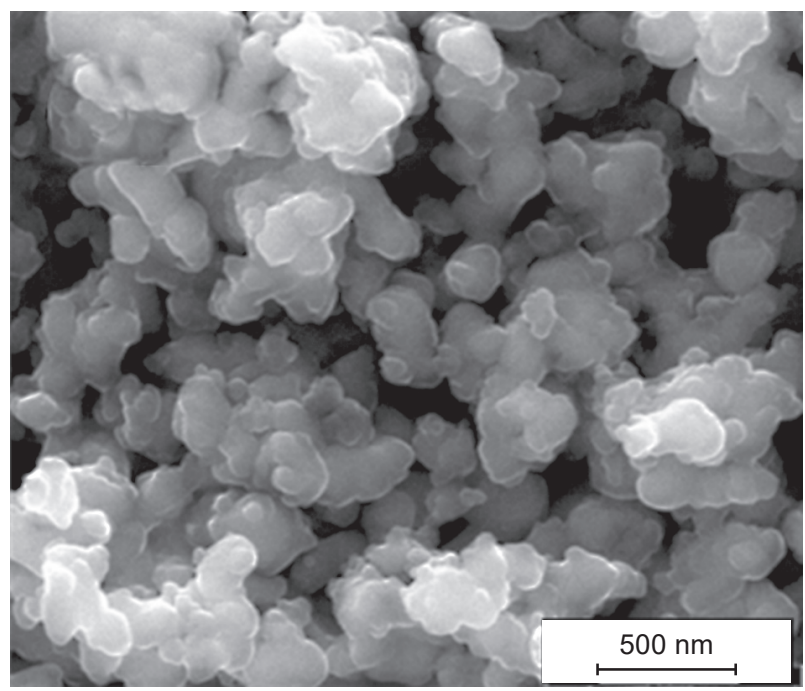

b)

Figure 1. SEM images of the micrometer-sized (a) and nanometer-sized (b) $\mathrm{Al}_{2} \mathrm{O}_{3}$ powders 
The scanning electron microscopy were carried out on a Field Emission Scanning Electron Microscope (FE-SEM, Quanta FEG 250, FEI Corporation, US). The crystalline phase of the sintered ceramics was analyzed using X-ray diffraction (XRD) on a diffractometer (D8Advance, Bruker Corporation, Germany). The density of ceramics was measured based on the Archimedes principle.

\section{RESULTS AND DISCUSSION}

It can be seen from Figure 1a the micrometer sized $\mathrm{Al}_{2} \mathrm{O}_{3}$ powder mainly consists of rod-like particles with a thickness and length of $2-3 \mu \mathrm{m}$ and $3-10 \mu \mathrm{m}$, respectively. From Figure 1b, the particle size of the nano $\mathrm{Al}_{2} \mathrm{O}_{3}$ powder is about $50 \mathrm{~nm}$. Agglomeration of the particles is observed in both cases.

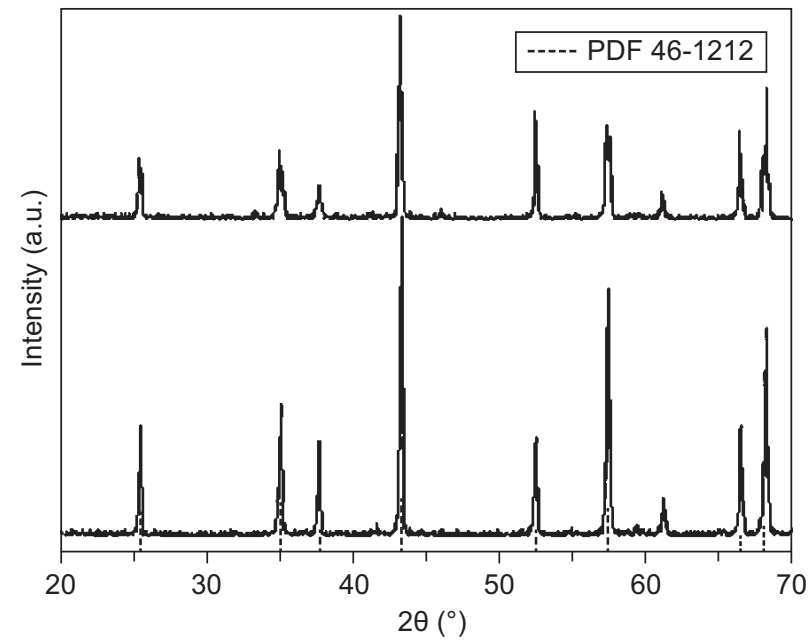

Figure 2. XRD patterns of sintered MAP ceramic (a) and sintered NAP ceramic (b).

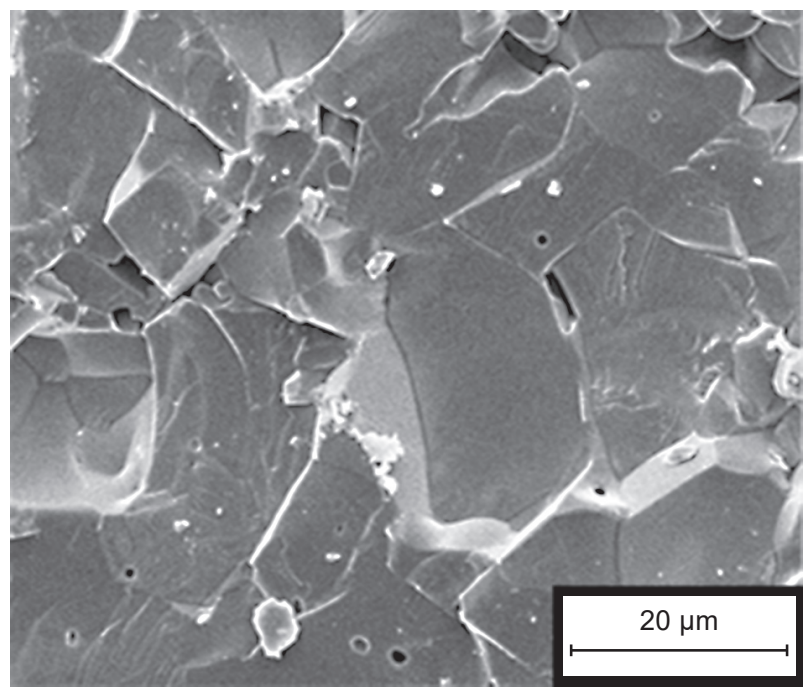

a)
The XRD patterns of the sintered $\mathrm{Al}_{2} \mathrm{O}_{3}$ ceramics indicate that both the MAP and the NAP ceramics have corundum $\left(\alpha-\mathrm{Al}_{2} \mathrm{O}_{3}\right.$, PDF 46-1212) as crystalline phase. However, the diffraction peaks of the NAP ceramic are higher and sharper than those of the MAP ceramic.

The fracture surface of the MAP ceramic is shown in Figure $3 \mathrm{a}$. This image shows that the size of the crystals in the MAP ceramics is about $10-50 \mu \mathrm{m}$. In addition, both transgranular and intergranular fracture modes are observed in the MAP specimen. In contrast, Figure $3 \mathrm{~b}$ indicates that the NAP ceramic consist of crystals sized around $20-100 \mu \mathrm{m}$. Also, the transgranular fracture mechanism is predominant.

The densities of the $\mathrm{Al}_{2} \mathrm{O}_{3}$ ceramic specimens are shown in Table 1. The larger relative density of the NAP ceramic suggests that it is more densified than the MAP ceramic, proving the positive effect of the included nanopowder on the sintering process of the ceramic.

Table 1. The density and flexural strength of the prepared $\mathrm{Al}_{2} \mathrm{O}_{3}$ ceramics.

\begin{tabular}{lcccc}
\hline Specimens & $\begin{array}{c}\text { Density } \\
\left(\mathrm{g} \cdot \mathrm{cm}^{-3}\right)\end{array}$ & $\begin{array}{c}\text { Density } \\
\text { ratio } \\
(\%)\end{array}$ & $\begin{array}{c}\text { Average flexural } \\
\text { strength } \\
(\mathrm{MPa})\end{array}$ & $\begin{array}{c}\text { Standard } \\
\text { deviation } \\
(\mathrm{MPa})\end{array}$ \\
\hline MAP ceramic & 3.81 & 96.0 & 312 & 23.2 \\
NAP ceramic & 3.86 & 97.2 & 318 & 18.6 \\
\hline
\end{tabular}

The average flexural strength and standard deviation of 30 pieces of MAP ceramic specimens are $312 \mathrm{MPa}$ and $23.2 \mathrm{MPa}$, respectively, while the values of 30 pieces of NAP ceramic specimens are $318 \mathrm{MPa}$ and 18.6 $\mathrm{MPa}$, respectively. The data are not significantly different. However, if the data are grouped with an interval of $10 \mathrm{MPa}$ and plotted (Figure 4), it can be seen that the distribution of these data is different.

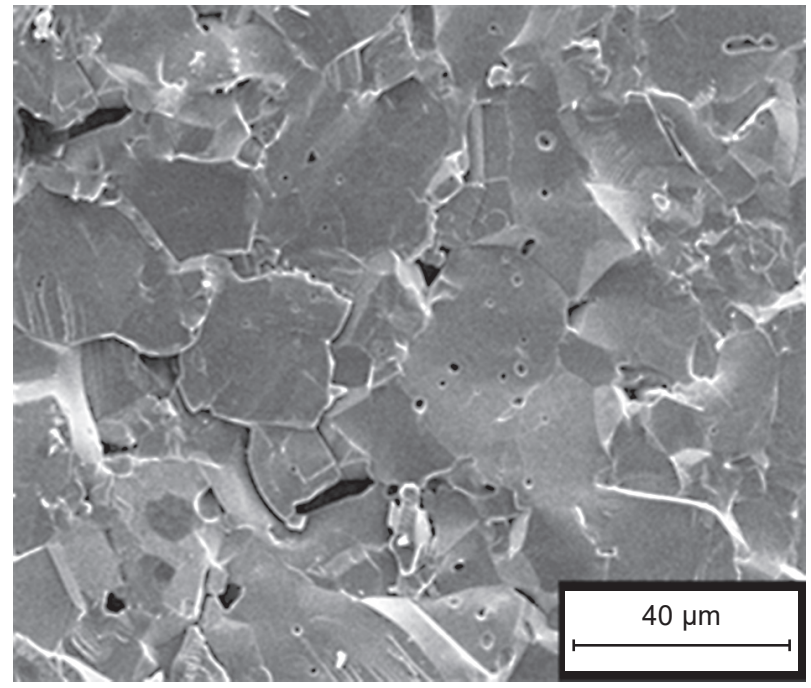

b)

Figure 3. SEM images of sintered MAP (a) and NAP (b) ceramics. 
Guo D., Liu S.

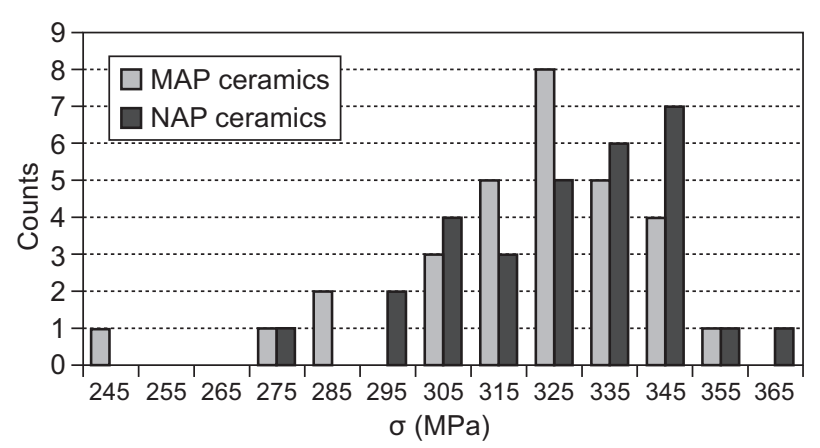

Figure 4. Distribution of $\mathrm{Al}_{2} \mathrm{O}_{3}$ ceramics flexural strength.

Following the aforementioned steps of the Weibull distribution model analysis, the data listed in Table 2 and 3 are the measured flexural strength $\sigma_{i}$, the fracture probability $P_{\mathrm{i}}$ calculated from Equation 2, the values $\ln \ln \left[1 /\left(1-P_{\mathrm{i}}\right)\right]$ and $\ln \sigma_{\mathrm{i}}$ calculated from Equation 3 and 4.

First, the relationship between the flexural strength $\sigma$ and fracture probability $P_{\mathrm{i}}$ of the MAP ceramics and NAP ceramics is demonstrated in Figure 5. It can be seen that the relationship between the flexural strength $\sigma$ and the fracture probability $P_{\mathrm{i}}$ is nonlinear. Therefore, it is difficult to specify the fracture probability of the $\mathrm{Al}_{2} \mathrm{O}_{3}$ ceramics simply by the probability versus strength curve depicted in Figure 5. To overcome this problem,

Table 2. The flexural strength $(\sigma)$ and fracture probability $P_{i}$ of the MAP ceramic.

\begin{tabular}{ccccc}
\hline$i$ & $\sigma(\mathrm{MPa})$ & $\ln \sigma_{i}$ & $P_{i}$ & $\ln \ln \left[1 /\left(1-P_{i}\right)\right]$ \\
\hline 1 & 247.943 & 5.51320 & 0.02296 & -3.76246 \\
2 & 271.233 & 5.60298 & 0.05586 & -2.85634 \\
3 & 282.287 & 5.64293 & 0.08876 & -2.37574 \\
4 & 282.710 & 5.64442 & 0.12166 & -2.04240 \\
5 & 303.019 & 5.71379 & 0.15456 & -1.78443 \\
6 & 304.035 & 5.71714 & 0.18745 & -1.57222 \\
7 & 307.775 & 5.72937 & 0.22035 & -1.39065 \\
8 & 310.230 & 5.73732 & 0.25325 & -1.23091 \\
9 & 310.379 & 5.73779 & 0.28615 & -1.08742 \\
10 & 318.016 & 5.76210 & 0.31905 & -0.95642 \\
11 & 318.196 & 5.76267 & 0.35195 & -0.83520 \\
12 & 318.268 & 5.76289 & 0.38485 & -0.72178 \\
13 & 320.654 & 5.77036 & 0.41775 & -0.61461 \\
14 & 320.940 & 5.77125 & 0.45065 & -0.51247 \\
15 & 322.279 & 5.77542 & 0.48355 & -0.41435 \\
16 & 322.363 & 5.77568 & 0.51644 & -0.31939 \\
17 & 322.478 & 5.77603 & 0.54934 & -0.22684 \\
18 & 322.924 & 5.77742 & 0.58224 & -0.13599 \\
19 & 326.606 & 5.78876 & 0.61514 & -0.04617 \\
20 & 329.050 & 5.79621 & 0.64804 & 0.04329 \\
21 & 330.095 & 5.79938 & 0.68094 & 0.13311 \\
22 & 332.861 & 5.80772 & 0.71384 & 0.22410 \\
23 & 335.918 & 5.81687 & 0.74674 & 0.31724 \\
24 & 337.714 & 5.82220 & 0.77964 & 0.41375 \\
25 & 337.925 & 5.82282 & 0.81254 & 0.51531 \\
26 & 341.473 & 5.83327 & 0.84543 & 0.62441 \\
27 & 344.587 & 5.84235 & 0.87833 & 0.74501 \\
28 & 346.753 & 5.84861 & 0.91123 & 0.88448 \\
29 & 349.132 & 5.85545 & 0.94413 & 1.05944 \\
30 & 357.425 & 5.87893 & 0.97703 & 1.32802 \\
\hline & & & & \\
\hline
\end{tabular}

$\ln \ln \left[1 /\left(1-P_{\mathrm{i}}\right)\right]$ versus $\ln \sigma$ curve are plotted in Figure 6. Both curves are linear, suggesting that the mechanical behavior of the two prepared alumina ceramics can be described by the Weibull distribution model. After calculation and transformation, the Weibull distribution equations of the ceramics are given by Equations 7 and 8 .

For the MAP ceramics:

$\ln \ln \left[1 /\left(1-P_{f}\right)\right]=14.921 \ln \sigma-14.921 \ln 330.304$

For the NAP ceramics:

$\ln \ln \left[1 /\left(1-P_{f}\right)\right]=19.673 \ln \sigma-19.673 \ln 334.976$

Based on these two equations, the Weibull modulus, $m$, and the characteristic rupture modulus, $M O R_{0}$, of the 30 tested specimens of the MAP and NAP ceramics are obtained (Table 4). The results indicate that the Weibull modulus of the NAP ceramic (19.673) is $31.8 \%$ larger than that of the MAP ceramic. It means that the distribution of the flexural strength of the NAP ceramic is more concentrated than that of the MAP ceramic. Therefore, the data of the flexural strength of the NAP ceramics are more stable and reliable. This will benefit an accurate prediction of the loading capacity of the prepared ceramic and a reliable determination of its application conditions.

Table 3. The flexural strength $(\sigma)$ and fracture probability $P_{i}$ of the NAP ceramic.

\begin{tabular}{ccccc}
\hline$i$ & $\sigma(\mathrm{MPa})$ & $\ln \sigma_{i}$ & $P_{i}$ & $\ln \ln \left[1 /\left(1-P_{i}\right)\right]$ \\
\hline 1 & 275.699 & 5.61931 & 0.02296 & -3.76246 \\
2 & 298.364 & 5.69832 & 0.05586 & -2.85634 \\
3 & 299.111 & 5.70081 & 0.08876 & -2.37574 \\
4 & 300.991 & 5.70708 & 0.12166 & -2.04240 \\
5 & 303.845 & 5.71652 & 0.15456 & -1.78443 \\
6 & 306.310 & 5.72460 & 0.18745 & -1.57222 \\
7 & 309.783 & 5.73587 & 0.22035 & -1.39065 \\
8 & 311.859 & 5.74255 & 0.25325 & -1.23091 \\
9 & 317.933 & 5.76184 & 0.28615 & -1.08742 \\
10 & 318.406 & 5.76333 & 0.31905 & -0.95642 \\
11 & 321.286 & 5.77233 & 0.35195 & -0.83520 \\
12 & 323.550 & 5.77935 & 0.38485 & -0.72178 \\
13 & 324.154 & 5.78122 & 0.41775 & -0.61461 \\
14 & 326.988 & 5.78992 & 0.45065 & -0.51247 \\
15 & 328.908 & 5.79578 & 0.48355 & -0.41435 \\
16 & 330.174 & 5.79962 & 0.51644 & -0.31939 \\
17 & 330.563 & 5.80080 & 0.54934 & -0.22684 \\
18 & 331.271 & 5.80294 & 0.58224 & -0.13599 \\
19 & 331.978 & 5.80507 & 0.61514 & -0.04617 \\
20 & 332.325 & 5.80611 & 0.64804 & 0.04329 \\
21 & 336.367 & 5.81820 & 0.68094 & 0.13311 \\
22 & 340.191 & 5.82951 & 0.71384 & 0.22410 \\
23 & 340.638 & 5.83082 & 0.74674 & 0.31724 \\
24 & 344.814 & 5.84301 & 0.77964 & 0.41375 \\
25 & 346.349 & 5.84745 & 0.81254 & 0.51531 \\
26 & 346.593 & 5.84815 & 0.84543 & 0.62441 \\
27 & 347.272 & 5.85011 & 0.87833 & 0.74501 \\
28 & 349.569 & 5.85670 & 0.91123 & 0.88448 \\
29 & 351.814 & 5.86310 & 0.94413 & 1.05944 \\
30 & 360.043 & 5.88622 & 0.97703 & 1.32802 \\
\hline
\end{tabular}

Ceramics - Silikáty 60 (2) 99-104 (2016) 


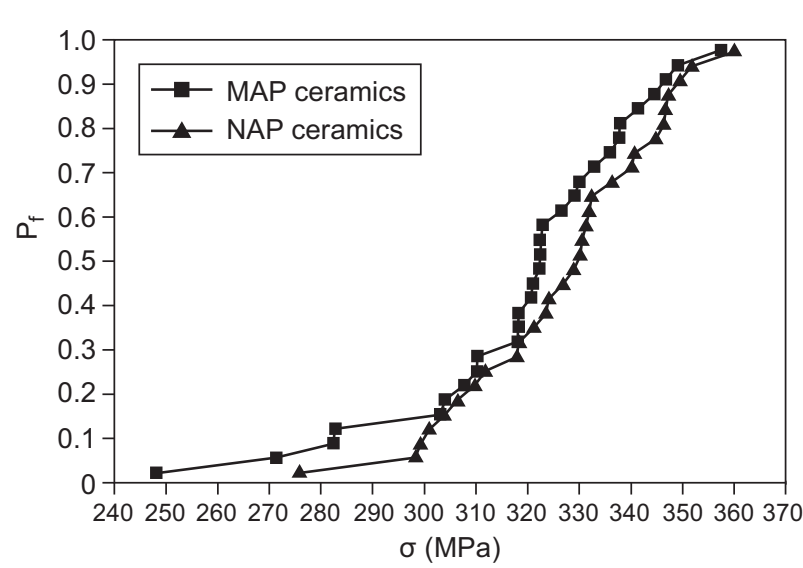

Figure 5. The relationship between the flexural strength $\sigma$ and the fracture probability $P_{i}$ of the $\mathrm{Al}_{2} \mathrm{O}_{3}$ ceramics.

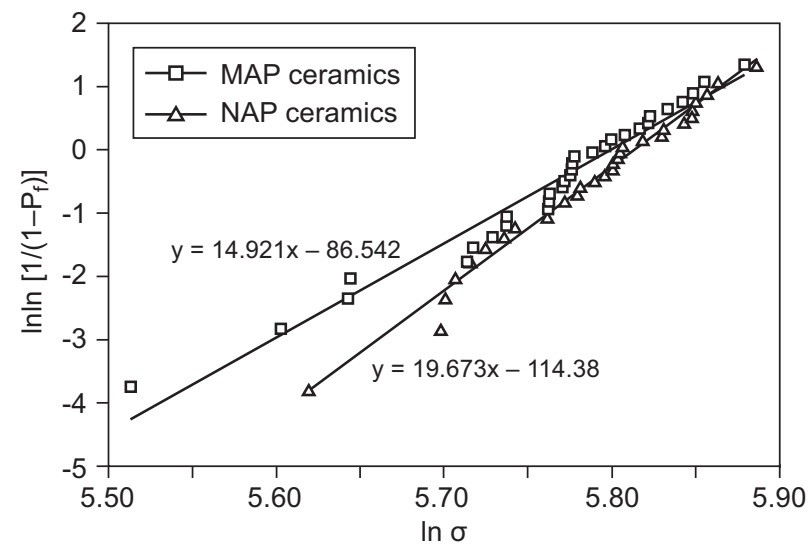

Figure 6. Weibull distribution of flexural strength of $\mathrm{Al}_{2} \mathrm{O}_{3}$ ceramics.

Table 4. The Weibull modulus and the characteristic rupture modulus of the $\mathrm{Al}_{2} \mathrm{O}_{3}$ ceramics.

\begin{tabular}{lccc}
\hline Specimens & $\begin{array}{c}\text { Number of } \\
\text { tested } \\
\text { specimens }\end{array}$ & $\begin{array}{c}\text { Weibull } \\
\text { modulus } \\
m\end{array}$ & $\begin{array}{c}\text { Characteristic } \\
\text { rupture modulus } \\
\text { MOR }_{0}\end{array}$ \\
\hline MAP ceramic & 30 & 14.921 & 330.304 \\
NAP ceramic & 30 & 19.673 & 334.976 \\
\hline
\end{tabular}

\section{CONCLUSION}

Adding $5 \mathrm{wt}$ \% of nanometer sized alumina powder in micrometer sized alumina powder benefits to form alumina ceramic with larger crystals and results in a favorable transgranular fracture mechanism. Although the nanopowder adding does not signally increase the mechanical strength of the ceramic in this work, the Weibull distribution analysis on the flexural strength of 30 pieces of NAP and MAP ceramics suggest that the Weibull modulus of the NAP ceramic $\left(m_{\mathrm{NAP}}=19.673\right)$ is greater than that of the MAP ceramics $\left(m_{\mathrm{MAP}}=14.921\right)$. Therefore, the distribution of the flexural strength of the NAP ceramics is more concentrated and the experimental data are more stable and reliable, beneficial to determine the application conditions of the prepared alumina samples.

Acknowledgement

This work was financially supported by the National Key Scientific Instruments and Equipment Development Special Fund (2011 YQ14014510).

\section{REFERENCES}

1. Wang L.S. (2005): Special ceramics. $2^{\text {nd }}$ ed., Central South University Press, Changsha.

2. Griffith A.A. (1921): The phenomena of rupture and flow in solids. Philosophical transactions of the royal society of London A, 221, 163-198.

3. Gong J.H. (2001): Fracture mechanics of ceramics. $1^{\text {st }}$ ed., Tsinghua University Press, Beijing.

4. Weibull W. (1951): Wide applicability. Journal of applied mechanics, 103, 293-297.

5. Jin Z.Z., Bao Y.W. (1996): Characterization of Mechanical Properties for Brittle Materials and Ceramics. $1^{\text {st }}$ ed., China Railway Press, Beijing.

6. Ma X.M., Zhang S.J., Hu L.Q., Cao R.F., Liu P., Luo L., Wu Y.C. (2007): An improved rank assessment method for weibull analysis of reliability data. Chinese Journal of Nuclear Science and Engineering, 27, 152-155.

7. Khabas T.A., Maletina L.V., Kamyshnaya K.S. (2014): Influence of nanopowders and pore-forming additives on sintering of alumma-zircorna ceramics. IOP Conference Series: Materials Science and Engineering. 66(1), 012050. doi:10.1088/1757-899X/66/1/012050

8. Li S.B., Chen Z.H., Zhao Y.M., Wang Z.Y., Tang L.H., Zhao X.Y., Chen J.W., Xie C., Li X.N. (2007): Mechanical properties and microstructure of partially sintered zirconia ceramics. Key Engineering Materials, 368, 1252-1254. doi:10.4028/www.scientific.net/KEM.368-372.1252

9. Eser O., Kurama S. (2010): The effect of the wet-milling process on sintering temperature and the amount of additive of SiAlON ceramics. Ceramics International, 36(4), 12831288. doi:10.1016/j.ceramint.2009.12.025

10. Brito-Chaparro J.A., Aguilar-Elguezabal A., Echeberria J., Bocanegra-Bernal M.H. (2009): Using high-purity $\mathrm{MgO}$ nanopowder as a stabilizer in two different particle size monoclinic $\mathrm{ZrO}_{2}$ : Its influence on the fracture toughness. Materials Chemistry and Physics, 114(1), 407-414. doi:10.1016/j.matchemphys.2008.09.058

11. Hellmig R.J., Ferkel H. (2001) Using Nanoscaled Powder as an Additive in Coarse-Grained Powder. Journal of the American Ceramic Society, 84(2), 261-266. doi:10.1111/j.1151-2916.2001.tb00647.x

12.He J.L., Yu D.L., Diao Y.Q., Tian Y.J., Li D.C. (2000): Influence of nano-sized $\gamma-\mathrm{Al}_{2} \mathrm{O}_{3}$ powder on sintering characteristics of alumina and silicon carbide fibers. Acta Materiae Compositae Sinica, 17, 80. 
13.Li J., Pan Y.B., Ning J.W., Hang L.P., Guo J.K. (2003): Low Temperature Sintering of Bimodal Alumina Powder Mixtures with Nanocrystalline Component [J]. Journal of Inorganic Materials, 6, 007.J.

14.Zhao J., Wang Z., Xing G.H., Sun X. (2009): Influence of nano- $\mathrm{Al}_{2} \mathrm{O}_{3}$ on the mechanical properties and microstructure of alumina ceramic. Journal of the University of Jinan (science and technology edition), 23, 138-140. (in Chinese)
15.Vozdecky P., Roosen A., Knieke C., Peukert W. (2010): Direct tape casting of nanosized $\mathrm{Al}_{2} \mathrm{O}_{3}$ slurries derived from autogenous nanomilling. Journal of the American Ceramic Society, 93(5), 1313-1319. doi:10.1111/j.15512916.2009.03597.x 